\title{
Cognitive ability and psychological effectiveness of brain training dance robot therapy for elderly people
}

\author{
Kazue Sawami*1, Mitsuo Kimura1', Tetsuro Kitamura1, Masahiko Kawaguchi', Mihoko Furusumi', Chizuko \\ Suishu², Naoko Morisaki3 ${ }^{3}$, Sonomi Hattori ${ }^{4}$
}

\begin{abstract}
${ }^{*}$ Correspondence
Kazue Sawami

Nara Medical University, Japan

Email: sawami@naramed-u.ac.jp

${ }^{1}$ Nara Medical University, Japan

2Shubun University, Japan

${ }^{3}$ Himeji University, Japan

4Wakayama Medical University, Japan

Received: Feb 18, 2019

Accepted: Jun 14, 2019

Published: Jun 20, 2019

(C2019 Kazue Sawami et al; licensee OA Journal of Neuropsychiatry. This is an Open Access article distributed under the terms of the Creative Commons Attribution License (http://

creativecommons.org/licenses/by/4.0), which permits unrestricted use, distribution, and reproduction in any medium, provided the original work is properly credited.
\end{abstract}

\begin{abstract}
Introduction: Regarding dementia prevention, as it has been reported that the volume of hippocampus increase with continuous dancing and that dancers' gray matter increases, dancing and recognition tasks have been combined and developed into brain training. Furthermore, we equipped a robot with dance therapy and a cognitive evaluation scale, the results of which we will exam as the focus of this study.
\end{abstract}

Methods: Comparison of the results of cognitive evaluation tests before and after 7 weeks of continuous cognitive dance therapy once a week. The cognitive evaluation test utilized was the cognitive test used by the National Police Agency for the renewal of elderly person's licenses. Moreover, mental states before and after dance were compared on a five-level Likert scale, and we surveyed the psychological condition of participants after robot therapy.

Results: Of the 91 registrants, with no missing values data of 71 people was analyzed with paired t-test. The mean age was $70.3 \pm 5.7$ years old, the average score for the cognitive test prior to intervention was 86.8 points. After 7 weeks of intervention,

the average score was 94.7 points, significant increase $(p<0.01)$. At the Likert scale of the mental state, there was a significant improvement in mood comfort, satisfaction, and vitality $(p<0.01)$. And there was a correlation between cognitive function and mental state $(p<0.05)$. Next, the average score of the robot therapy satisfaction level was as high as 4.73 out of 5 points. In the comments section, there were in descending order comments such as being happy, healing, clarity of the mind, facilitation of social interactions, et cetera.

Conclusion: Cognitive dance therapy improves cognitive ability. Remembering songs and choreography together with music is indeed easy and effective. Additionally, with the combined effects of the results from robot psychological healing, it was shown that both the mind and body of older people are revitalized.

Keywords: Brain training, Dance therapy, Robot therapy, Cognitive function, Psychological effectiveness. 


\section{Introduction}

With regards to the prevention of dementia, the effects of aerobic exercise are well known [1, 2], but a lot of motivation is necessary to continually do aerobic exercise every day $[\underline{3}, 4]$. For that reason, we surveyed the possibility of continuously doing various aerobic exercises, selected dance for its continuity $[\underline{5}, \underline{6}]$. Dance does not only improve one's physical ability in terms of one's ability to move or walk $[\underline{7}, \underline{8}]$, it improves one's mental health and prevents stress $[\underline{5}, \underline{9}]$.

Furthermore, regarding the effects of dance on the brain, dancers have an amount of gray matter and with continued dancing [10], the volume of hippocampus increases [11], with 6 weeks of balance training, there is evidence of increased gray matter [12]. For this reason, we developed brain training which combines dance with cognitive recognition tasks. For the pre-test, we compared a group that danced with a group that did not dance and found that cognitive ability improved and stress decreased $[\underline{5}, \underline{6}]$. Additionally, we equipped a robot with a dance therapy, making it possible to assign dance and cognitive tasks.

The background for this request is the aging of populations has continued on a global scale, and there has been an insufficient supply of nursing professionals as a result. Robots have the potential to respond to this demand by fulfilling everimportant roles in the field of nursing [13]. While the field of nursing and caregiver robots has seen advances at a rapid pace, there has been insufficient research as to the psychological effects of robot therapy. What we expect from robot therapy goes beyond satisfying the demand for caregiver. Robots can be used to mitigate stress [14], deter dementia and depression and aid in therapeutic exercises, thus providing a large benefits to the elderly, their family and health-care providers.

Furthermore in preliminary testing, we examined delayed playback task and the validity of dual task $[15,16]$, and developed cognitive-dance therapy to add delayed playback task and dual task as part of brain training [5]. If robots are able to perform health-care functions as outlined above, the societal benefits would be enormous. We thus equipped robots with brain training functions such as cognitive-dance therapy. Furthermore, to measure dementia we built in the Revised Hasegawa Dementia Scale (HDS-R) [17], and to measure mild cognitive impairment we added a cognitive evaluation scale for driver's licences [18], allowing the robot to detect the results of treatment and continuously understand changes in cognitive function. The primary objective of this research are verification of cognitive-dance therapy, and understanding how robot therapy affects treatment recipients.

This research received assistance from the Ministry of Health, Labour and Welfare's dementia policy research fund [19], and brain training by dance was developed in collaboration with the Nippon Street dance Studio Association, but there are no conflicts of interest to report.

\section{Methods}

1: Comparison of the before and after effects of cognitive dance therapy in order to program the robot. Method of cognitive dance therapy:

1. memorize 10 words; 2. practice a choreography assignment; 3. reproduce 10 words; 4 . reproduce the choreography assignment; 5 . sing while dancing; 6 . reproduce remembered lyrics.

In this way we alternatingly repeat memory assignments and dancing, with all participants supporting each other as they reproduce memory assignments.

Cognitive dance therapy is practiced once a week for 90 minutes, administering a cognitive test before and after 7 weeks of therapy, comparing them by the paired t-test.

For the cognitive test, the cognitive evaluation scale for National Police Agency of driver's licenses was used. The test used the following 3 tasks to decide test subjects' memory and cognitive ability.

(1) Date, day, and time-oriented tasks

(2) Delayed playback tasks

(3) Clock-drawing tasks

The standard values for test scores were determined based on the following:

(1) Normal: 76 points or more

(2) Mild cognitive decline: above 49 points, up to 76 points

(3) Cognitive decline: up to and below 49 points 
2: The state of mind was investigated on a 5-step Likert scale. There are four survey items: comfort, satisfaction, stress, and vitality.

3: The robots were communication robots, and primarily intervened through conversation and cognitive-dance therapy (Figure 1). We performed a questionnaire of elderly people who have undergone robot therapy. The satisfaction was measured using a 5-point Likert scale and included a free-form qualitative section.

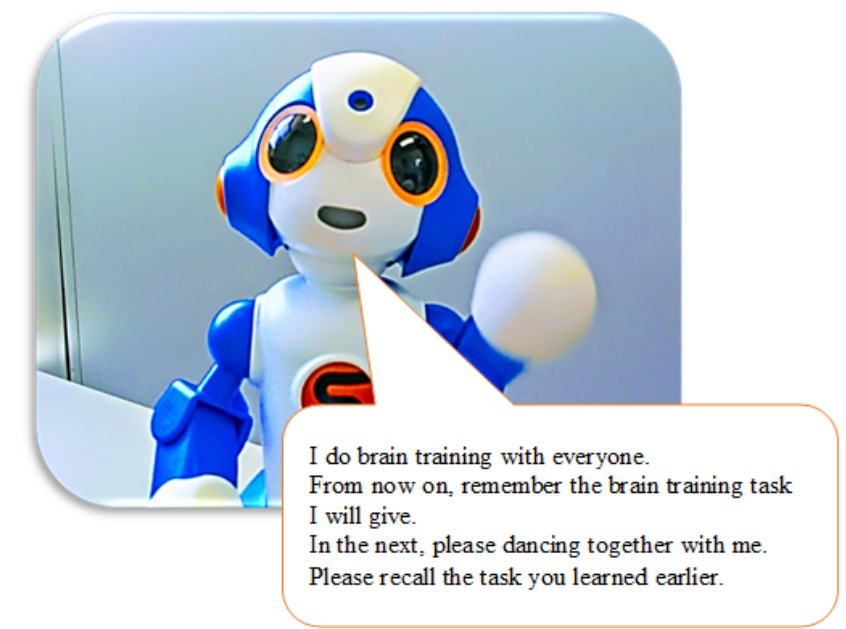

Figure 1. Conversation and cognitive-dance therapy by robots.

Cognitive tests and psychological status surveys were conducted before and when 7 interventions were completed. The analysis was performed before and after with a paired $T$ test, and the correlation between cognitive and psychological scores was revealed by Spearman's rank correlation coefficient.

\section{Method of participant recruitment:}

Applicants were registered by public offering. Not having dementia, and being able to take a test on their own without assistance.

\section{Implementation period:}

October 2018 - April 2019

\section{Ethical considerations}

The outline of the research, voluntary nature of participation, anonymity, and agreement regarding the publication of the document were explained to prospective participants both in writing and verbally, and their consent was subsequently obtained. The study protocol was approved by the ethical review board of Nara Medical University.
Regarding conflicts of interest, it has been confirmed that there is no conflict of interest at the Nara Medical University COI Committee.

\section{Results}

Of the 91 registrants, with no missing values, the data of 71 people was analyzed with the paired t-test. The mean age was $70.3 \pm 5.7$ years old, 8 of whom were men, 63 of whom were women. Regarding cognitive test results, total test scores surpassed the cutoff of 76 points even prior to intervention, with the average score being 86.8 points. After 7 weeks of intervention, the average score was 94.7 points, a substantial increase $(p<0.01)$. In regards to before and after comparisons of scores for each test subject, delayed playback task $(p<0.01)$ and clock-drawing $(p<0.05)$ improved substantially (Table 1 ).

Table 1. The paired t-test for mean of cognitive test scores.

\begin{tabular}{|l|c|c|c|c|}
\hline & \multicolumn{4}{|c|}{ Score of cognitive test } \\
\hline & $\begin{array}{c}\text { Orientatio } \\
\mathrm{n} \text { tasks }\end{array}$ & $\begin{array}{c}\text { Delayed } \\
\text { playback } \\
\text { tasks }\end{array}$ & $\begin{array}{c}\text { Clock- } \\
\text { drawing } \\
\text { tasks }\end{array}$ & $\begin{array}{c}\text { Total } \\
\text { score }\end{array}$ \\
\hline $\begin{array}{l}\text { Before } \\
\text { intervention }\end{array}$ & 17.1 & 49.4 & 20.3 & 86.8 \\
\hline $\begin{array}{l}\text { After } \\
\text { intervention }\end{array}$ & 17.2 & $56.7^{\star \star}$ & $20.7^{\star}$ & $94.7^{\star \star}$ \\
\hline $\begin{array}{l}\text { Significant } \\
\text { difference }\end{array}$ & 0.42 & 0.00 & 0.01 & 0.00 \\
\hline
\end{tabular}

As for psychological evaluation, as shown in Table 2, comfort, satisfaction, and vitality improved significantly $(p<0.01)$.

Table 2. The paired t-test for mean of psychological status

\begin{tabular}{|l|c|c|c|c|c|}
\hline & \multicolumn{5}{|c|}{ Score of psychological status } \\
\hline & Comfort & Satisfaction & Stress & Vitality & $\begin{array}{c}\text { Total } \\
\text { score }\end{array}$ \\
\hline $\begin{array}{l}\text { Before } \\
\text { intervention }\end{array}$ & 2.82 & 2.82 & 2.90 & 2.66 & 11.20 \\
\hline $\begin{array}{l}\text { After } \\
\text { intervention }\end{array}$ & $3.24^{\star \star}$ & $3.28^{\star \star}$ & 3.20 & $3.02^{\star \star}$ & $12.47^{\star}$ \\
\hline $\begin{array}{l}\text { Significant } \\
\text { difference }\end{array}$ & 0.00 & 0.00 & 0.17 & 0.00 & 0.03 \\
\hline
\end{tabular}


In addition, the total score on the cognitive scale and each score on the psychological scale were correlated, and the higher the cognitive score, the better the state of psychology (Table 3 ).

Table 3. Correlation between total score of cognitive test and each psychology scaleSpearman's rank correlation coefficient

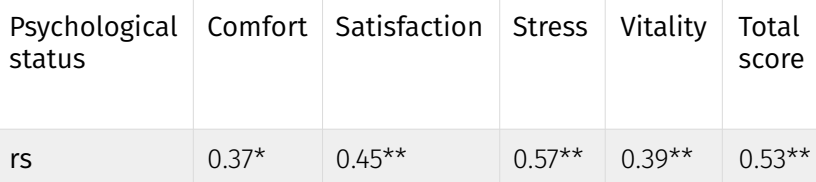

Among them, it was stress level that showed the strongest correlation with the score of cognitive test ( $r s=0.57$ ), figure 2. As for the stress level score, the higher the value, the more stress-free, and the higher the cognitive score the lower the stress.

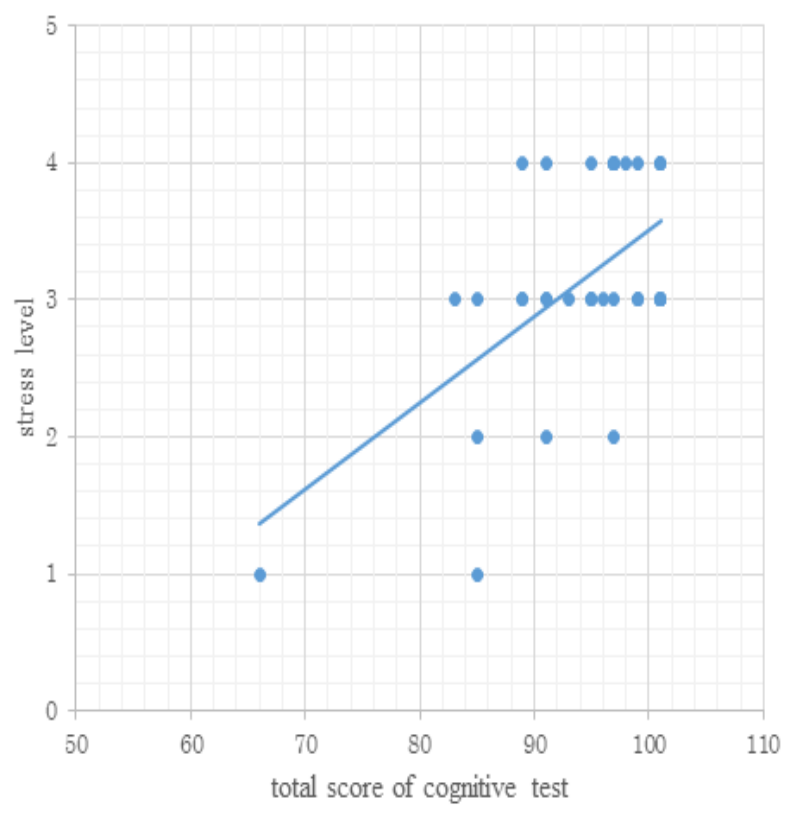

Figure 2. Correlation between total score of cognitive test and stress level Spearman's rank correlation coefficient $=0.57$.

Next, we analyzed satisfaction levels before and after robot therapy based on the data of 43 people with no missing values. The average score of the robot therapy satisfaction level is as high as 4.73 out of 5 points. In the free-form qualitative section, 43 people write that they are feeling pleasure, 42 write that it is good for brain activation, psychologically healing (41), promotes interactions (32), feeling excited (21), eases the atmosphere (17), in multiple answers (Figure 3).

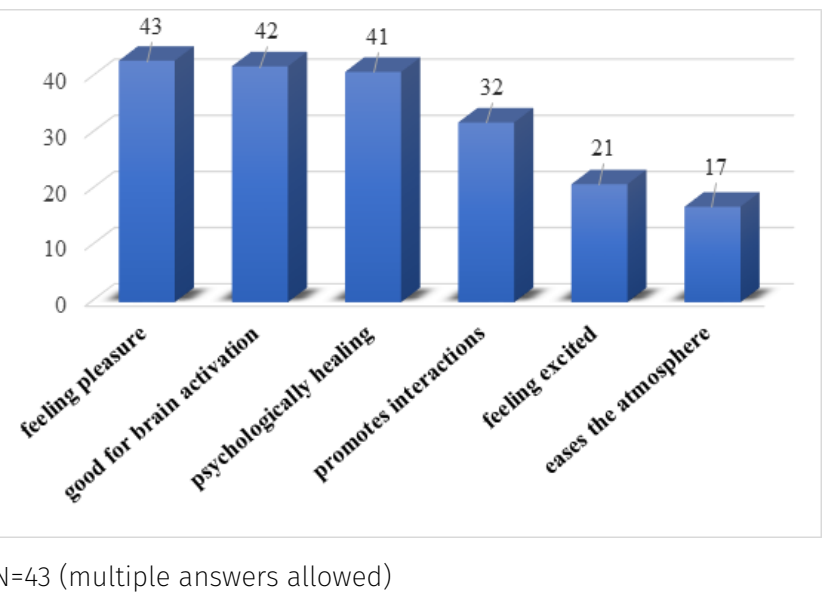

Figure 3. Content of the free-form questionnaire.

\section{Discussion}

As a method of cognitive training to maintain the cognitive ability is verified that dual-task (practicing two tasks simultaneously) [20, 21] and n-back task (to delay recall the nth time task) [22] is efficient. About the dual-task, in order to achieve the two tasks at the same time, it is necessary for the function of the frontal lobe that has prefrontal cortex as the center [23], and this thought that this leads to the training of the frontal lobe. In fact, it is verified from the examination that used the brain wave or the nearinfrared spectroscopy that the frontal lobe became activated [24, 25]. As for the n-back subject, the fact that was introduced by Wayne Kirchner in 1958, which states that even though it is a test of temporary memory, not only as an assessment test [26], but also it became clear that there is an effect of improvement in memorization and began to be used as a method for cognitive training. Facts such as the improvement of fluid intelligence [27], the increase in the density of dopamine [료], and according to the meta-analysis, the frontal lobe and the activation of the area of parietal cortex has been verified [22].

In examining methods for effectively conducting cognitive training such as this, we can say that dance choreography is a natural dual task. Furthermore, we also incorporated remembering choreography and lyrics afterwards. Additionally, in order to improve memorization ability, we added 10-word memory tasks. Looking at the before and after comparison for this study, we can see substantial improvement in cognitive scores. The big improvement regarding delayed playback task is especially significant. In our daily lives, we maintain memories temporarily, such 
as continuation of conversations, shopping and housework, and we act based on those.

This daily, essential temporary storage of memories is called a "Working memory" and research into improving this ability is advancing $[28,29]$. Language memory, visual-spatial recognition, et cetera are the foci of such training [30], which is also true of our methods.

However, what can be particularly noted is that the ability to combine music with natural movement and be able to train effortlessly is a special feature of our training method.

The method is to repeat the short term of musical phrases and the choreography several times and make target people reconstruct their memories after the cognitive-dance. Moreover, we change the choreography during the music and after that we conducted delayed recall. This has the characteristic that by memorizing along with the music, we can easily memorize and recall the phrases or the movements. In fact, the relevance between music and memorization is known [31], that music encourages the recollection of memories [32-34], and moreover it promotes the maintenance of the memories [35-37]. Furthermore, music improves the encoding capability of people's memory, which is to recognize the lyrics [38]. Lyrics indicated by songs can be remembered much better than clauses indicated by speech [39].

Furthermore, for implementing these by robots, we were able to confirm a high degree of satisfaction with regards to health-care intervention by robots. As per our qualitative analysis, the biggest reason for this was that feelings such as "feeling pleasure", followed by "good for brain activation", "psychologically healing" improved. Our communication robot was originally built with the goal of having positive psychological effects, and by adding brain training functions we were able to achieve not only pleasant feelings but also the increase of recollection ability, which constitute significant results.

As the result of using a communication robot created for the purpose of psychological healing for brain training, not only memory ability is improved but also there is a significant effect which makes participants' feeling more comfortable. Because stress and cognitive performance were correlated in our pre-test, $(p<0.05)$ [6] , our objective was to conduct the brain training without making participants' feel stress, and we achieved this objective. Furthermore, since the effects of promoting exchanges among participants and easing the atmosphere were observed, the robot played an important role for creating a positive atmosphere.

In this type of intervention, it is important to create an appropriate atmosphere for things go smoother. The fact that the robot can ease the atmosphere is found to be significant. Furthermore, since participants are gaining pleasure and excitement, the robots can be used for preventing depression or relieving stress for the future. Also, the brain activation effect is very significant, and it has been verified that such subjectivity has an effect on not developing dementia [40] or depression [41]. It has also been reported that subjective youthfulness can reduce the risk of developing dementi [42] and improve ability to perform tasks [43]. We therefore aim to develop the robot therapy while improving subjective sensations, such as brain activation and the feeling of excitement.

One of our goals was to confirm the psychological effects of robots, specifically the deterioration of stress as well the uplifting of spirits, which was confirmed in this research. Furthermore, if robots are able to monitor cognitive ability, they will not only be able to detect decreases in cognitive ability early, but also be able to respond and adopt preventative measures.

The cognitive screening test we installed was the cognitive evaluation scale for driver's licenses was a test that people over the age of 75 have to pass to renew their license, in which orientation tasks, delayed playback tasks, clock-drawing tasks is featured. Through assigning robots with such screening, it becomes easier to monitor the elderly's cognitive function in their home and facilities, allowing for a more systematic approach to dementia prevention. It would thus be ideal if robots can be used to mitigate stress and prevent depression through therapeutic exercises such as dance [5] and brain training $[\underline{15}, \underline{16}]$. Furthermore, we also found that intervention by robots fostered exchanges among participants and created a harmonious atmosphere. Interpersonal connections impact depression and stress [44], and interpersonal 
exchanges promotes a daily sense of reassurance [45], contributing to the health and well-being of the elderly [46]. Furthermore, these senses of health and well-being have a significant impact on healthy longevity [47].

Following the above, to increase the positive psychological effects due to robot therapy to its highest possible level, the robots' appearance, facial expressions and patterns of speech can be further improved, making them more easily approachable and friendly. We will develop this technique so that robots facilitate interpersonal communication among the elderly and give life a pleasure and vibrancy.

\section{Conclusion}

Cognitive dance therapy improves cognitive abilities, among which the delayed playback task has been improved the most. Remembering songs and choreography together with music is easy and can be continued on a daily basis. With the combined effects of the results from robot psychological healing, it could be confirmed that both the mind and body of older people are revitalized.

\section{Acknowledgment}

We would like to thank all the elderly people for participating in this project. In addition, we sincerely thank the staff at Nishikyo Ward Office Rakusai Branch Office Health \& Welfare Center and the Medical fitness Tomigaoka who cooperated. Furthermore, we want to thank everybody at Viston Corporation for their support in installing the brain training and rating scales into the robots.

\section{Funding}

This research received assistance from the Japanese Ministry of Health, Labour and Welfare's dementia policy research fund.

\section{References}

1. Suwabe K, Byun K, Hyodo K, et al. (2018) Rapid stimulation of human dentate gyrus function with acute mild exercise. Proc Natl Acad Sci U S A. 9:10487-10492.

2. Blumenthal JA, Smith PJ, Mabe S, et al. (2019) Lifestyle and neurocognition in older adults with cognitive impairments: A randomized trial. Neurology. 92:212-223.

3. Nakamura K, Furukawa M (2004) Examination of mental factor that affect the adherence volition of physical exercise Comparison of jogging and aerobic dance. Journal of Health and Sports Science, Juntendo University. 2:1-13.

4. Ohara S, Matushita T (2015) Research on Habituation and Continuation of Exercise and Sports. Aichi Institute of Technology. 50:58-70.

5. Sawami K, Kimura M, Kitamura T (2018) Verification of The Effect of Cognitive Training by Dance. Cli Med Cas Rep Stu: CMCRS. 110:1-6.

6. Sawami K, Kimura M, Kitamura T, et al. (2017) Verification of the Impact of Storage by the Rhythm Phrase to be Repeated. SciFed Publishers. 5:1-6.

7. Hackney ME, Earhart GM (2010) Effects of Dance on Gait and Balance in Parkinson Disease: A Comparison of Partnered and
Non-Partnered Dance Movement. Neurorehabil Neural Repair. 24:384-392.

8. McKinley P, Jacobson A, Leroux A, et al. (2008) Effect of a community-based Argentine tango dance program on functional balance and confidence in older adults. J Aging Phys Act. 16:435-453.

9. Helen P (2013) Dance Movement Therapy: Theory, Research, and Practice. Routledge Studies in Employment and Work Relations in Contex. Routledge.

10. Müller P, Rehfeld K, Schmicker M, et al. (2017) Evolution of neuroplasticity in response to physical activity in old age: the case for dancing. Front Aging Neurosci. ;9:56.

11. Rehfeld K, Müller P, Aye N, et al. (2017) Dancing or Fitness Sport? The Effects of Two Training Programs on Hippocampal Plasticity and Balance Abilities in Healthy Seniors. Front Hum Neurosci. 11:305.

12. Sehm B, Taubert M, Conde V, et al. (2014) Structural brain plasticity in Parkinson's disease induced by balance training. Neurobiol Aging. 35:232-239.

13. Robinson H, MacDonald B, Broadbent E. (2015) Physiological effects of a companion robot on blood pressure of older people in residential care facility: A pilot study. Australas J Ageing.34:27-32.

14. Shibata $T$ (2017) Development and spread of therapeutic medical robot, PARO: Innovation of non-pharmacological therapy for dementia and mental health. Inf Process Manag. 60:217-228.

15. Sawami K, Nakagawa H, Suishu C. (2017) Intellectual effects of delayed playback task and rhythmic activities. Ment Health Addict Res. 2:1-6.

16. Sawami K, Nakagawa $H$, Katahata $Y$, et al. (2017) Verification of Preventive Effect of Dual-Task and N-Back Task-Incorporated Music Therapy against Dementia. Neuropharm Open Access. 3:1-5.

17. Hasegawa K, Imai I (1989) Epidemiological study on ageassociated dementia in Japan. Diagnosis and treatment of senile dementia.

18. National Police Agency. Cognitive Impairment Screening Test for Senior Drivers, 2009.

19. Ministry of Health, Labour and Welfare. Dementia Policy Research Project, 2018.

20. Al-Yahya E, Johansen-Berg H, Kischka U, et al. (2016) Prefrontal Cortex Activation While Walking Dual-Task Conditions in Stroke: A Multimodal Imaging Study. Neurorehabil Neural Repair. 30:591-599.

21. Ohsugi H, Ohgi S, Shigemori K, et al. (2013) Differences in dualtask performance and prefrontal cortex activation between younger and older adults. BMC Neurosci.14:1-9.

22. Owen AM, McMillan KM, Laird AR, et al. (2005) N-back working memory paradigm: A meta-analysis of normative functional neuroimaging studies. Hum Brain Mapp. 25:46-59.

23. Yogev-Seligmann G, Hausdorff JM, Giladi N (2008) The role of executive function and attention in gait. Mov Disord. 23:329-342.

24. Holtzer R, Mahoney JR, Izzetoglu M, et al. (2011) fNIRS study of walking and walking while talking in young and old individuals. J Gerontol A Biol Sci Med Sci. 66:879-887.

25. Anguera JA, Boccanfuso J, Rintoul JL, et al. (2013) Video game training enhances cognitive control in older adults. Nature. 501:97-101.

26. Kirchner WK (1958) Age differences in short-term retention of rapidly changing information. J Exp Psychol. 55:352-358.

27. Susanne JM, Luethi SB, Buschkuehl M, et al. (2010) The relationship between $n$-back performance and matrix 
reasoning-implications for training and transfer. Intelligence. 38:625-635.

28. McNab F, Varrone A, Farde L, et al. (2009) Changes in Cortical Dopamine D1 Receptor Binding Associated with Cognitive Training. Science. 323:800-802.

29. Olesen PJ, Westerberg H, Klingberg T. (2004) Increase prefrontal and parietal activity after training of working memory. Nat Neurosci. 7:75-79.

30. Gathercole E S (2008) Working memory in the classroom. The Psychologist. 21:382-385.

31. Snyder R. Music and Memory-An Introduction. A Bradford Book, 2001.

32. Raglio A (2010) Dementia in Music Therapy. NonPharmacological Therapies in Dementia. 1-14.

33. Gomez GM, Gomez GJ (2017) Music therapy and Alzheimer's disease: Cognitive, psychological, and behavioural effects. Neurologia. 32:300-308.

34. Fang R, Ye S, Huangfu J, et al. (2017) Music therapy is a potential intervention for cognition of Alzheimer's Disease: A mini-review. Transl Neurodegener. 6:1-8.

35. Ozdemir L, Akdemir N (2009) Effects of multisensory stimulation on cognition, depression and anxiety levels of mildly-affected Alzheimer's patients. J Neurol Sci. 283:211-213.

36. Särkämö T, Tervaniemi M, Laitinen S, et al. (2014) Cognitive, emotional, and social benefits of regular musical activities in early dementia: randomized controlled study. Gerontologist. 54:634-650.

37. Herholz SC, Herholz RS, Herholz K (2013) Non-pharmacological interventions and neuroplasticity in early stage Alzheimer's disease. Expert Rev Neurother. 13:1235-1245.

38. Simmons-Stern NR, Budson AE, Ally BA (2010) Music as a memory enhancer in patients with Alzheimer's disease. Neuropsychologia. 48:3164-3167.
39. Wallace WT (1994) Memory for Music: Effects of Melody on Recall of Text. J Exp Psychol Learn Mem Cogn. 20:1471-1485.

40. Stephan Y, Caudroit J, Jaconelli A, et al. (2014) Subjective age and cognitive functioning: a 10-year prospective study. Am J Geriatr Psychiatry. 22:1180-1187.

41. Keyes CL, Westerhof GJ (2012) Chronological and subjective age differences in flourishing mental health and major depressive episode. Aging Ment Health. 16:67-74.

42. Rippon I, Steptoe A (2015) Feeling old vs being old: associations between self-perceived age and mortality. JAMA Intern Med. 175:307-309.

43. Ihira H, Furuna T, Mizumoto A, et al. (2015) Subjective physical and cognitive age among community-dwelling older people aged 75 years and older: differences with chronological age and its associated factors. Aging Ment Health. 19:756-761.

44. Hasegawa Y (2013) The Analyses of Stress Mediating Factors in Interpersonal Stress. Atomi University Departmental Bulletin Paper. 1:31-42.

45. Tanno H (2010) The function of friendship in QOL of older people. Interpersonal social psychology research. 10:125-129.

46. Sorkin DH, Rook KS, Heckhausen J, et al. (2009) Predicting Changes in Older Adults' Interpersonal Control Strivings. Int J Aging Hum Dev. 69:159-180.

47. Heidrich J, Liese AD, Löwel $H$, et al. (2002) Self-rated health and its relation to all-cause and cardiovascular mortality in southern Germany. Results from the MONICA Augsburg cohort study 1984-1995. Ann Epidemiol. 12:338-345. 